\title{
Agôn
}

Revue des arts de la scène

Critiques | Saison 2015-2016

\section{Het Land Nod (Le Pays de Nod), conception FC Bergman}

L'art comme ligne de fuite

\section{Caroline Châtelet}

\section{CpenEdition}

Journals

Édition électronique

URL : http://journals.openedition.org/agon/3975

DOI : 10.4000 /agon.3975

ISSN : 1961-8581

Éditeur

Association Agôn

Référence électronique

Caroline Châtelet, "Het Land Nod (Le Pays de Nod), conception FC Bergman », Agôn [En ligne], Critiques, mis en ligne le 28 juillet 2016, consulté le 23 septembre 2020. URL : http://journals.openedition.org/ agon/3975 ; DOI : https://doi.org/10.4000/agon.3975

Ce document a été généré automatiquement le 23 septembre 2020.

Association Agôn et les auteurs des articles 


\section{Het Land Nod (Le Pays de Nod), conception FC Bergman}

L'art comme ligne de fuite

Caroline Châtelet

\section{RÉFÉRENCE}

Het Land Nod - conception FC Bergman

Festival IN d'Avignon, du 13 au 23 juillet 2016 - Parc des Expositions d'Avignon

1 Voir un spectacle : programmé dans le cadre du festival IN d'Avignon; ayant bénéficié dès sa première d'un très bon accueil critique; interprété par une jeune compagnie flamande peu connue en France (FC Bergman de son petit nom, étrange intitulé balançant entre foot et cinéphilie), ces trois éléments - Avignon, validation critique, dimension de découverte - amplifiant l'attention autour du travail. Avoir entendu préalablement une interview des artistes, et savoir que la scénographie englobant les spectateurs dans le dispositif reproduit la salle Rubens du Musée des Beaux-Arts d'Anvers. Savoir, de même, que cette salle aux dimensions impressionnantes - qui a pour particularité de contenir des œuvres plus grandes que les portes - est à l'origine de la création. FC Bergman souhaitait en effet concevoir un projet in situ durant des travaux de réfection du musée et c'est l'impossibilité d'une telle réalisation qui a amené la conception de l'espace. Avoir parcouru quelques articles, certains soulignant la puissance poétique sans déroulement d'un sens précis, là où d'autres relèvent la pertinence d'une création qui aborde sans les illustrer des questions d'actualité. À travers diverses images et séquences parfois dansées pouvant rappeler le travail de la chorégraphe Sasha Waltz (par exemple), Het Land Nod évoquerait la situation politique européenne et ce qu'on appelle hypocritement la crise migratoire. Savoir, alors, en prenant place dans la salle, que pour vraiment voir ce qui va suivre, il va falloir oublier. Se détacher, faire abstraction de tout ce qui a été dit, lu, se méfier des discours, ne pas tenir compte de ce qui se joue déjà dans le public. Car - et c'est là l'une des spécificités 
des festivals - le «pré-contentement » guette, les rires surgissant aux moindres gestes des comédiens, parce que la presse est élogieuse, parce que les places s'arrachent, parce que la rumeur «c'est très drôle » exacerbent la réception. Pourtant, si Het Land Nod balance, surtout à ses débuts, plutôt du côté de la galéjade et d'un burlesque sur de menus gestes, le projet se teinte progressivement d'une inquiétude sourde. Dans cette salle aux murs hauts dont le papier peint a été retiré, tout nous indique qu'un chantier est en cours. Lorsque les spectateurs s'installent, quelques employés s'affairent, certains s'activant à l'emballage d'un tableau, tandis qu'un homme passe un aspirateur sous le regard d'un autre, en retrait à l'extérieur de la pièce. La seule œuvre encore aux murs s'avère être Le Coup de lance, de Rubens, immense peinture représentant le Christ en croix et la tentative de Marie-Madeleine de dévier le coup de lance du romain païen Longinus. Une référence chrétienne redoublant celle contenue par l'intitulé du spectacle, Het Land Nod (Le Pays de Nod) désignant le territoire où Caïn fuit après le meurtre de son frère Abel - territoire qu'on situe aujourd'hui... en Afghanistan. Pour autant, si la métaphore d'un lieu lointain, isolé, où les hommes seraient condamnés à l'errance plane sur tout le spectacle, c'est bien autour de l'œuvre de Rubens que tout va se jouer. Dans une succession de séquences sans paroles, divers personnages vont la côtoyer. Il y a, d'abord, les deux gardiens, un peu désœuvrés, passant régulièrement, communiquant par talkie-walkie et essayant tant bien que mal de réguler les débordements des visiteurs. Des touristes, aussi, caricatures du comportement des visiteurs dans les musées. D'autres, aux actions incongrues, comme cet homme qui après s'être dénudé demeurera prostré. Ou cette femme, qui ne cesse de choir, au sol ou dans les bras d'hommes de passage. De tout cela, on pourrait ne saisir qu'une succession plutôt plaisante, travaillant le burlesque et le dérisoire d'images tantôt drôles, souvent poétiques, parfois un peu faciles, étranges, magnétiques - comme cette course à plusieurs dans la salle, référence à une scène d'À bout de souffle de Jean-Luc Godard. Des séquences subtilement conçues et esthétiquement maitrisées, la création lumières rappelant le travail de Rubens. Ce serait omettre le second personnage principal, le conservateur, qui dialogue littéralement avec Le Coup de lance, ainsi que le rappelle la dernière scène. Solitaire, opiniâtre, ce dernier s'acharne à faire sortir la peinture de la salle, pour, on l'imagine, mener les travaux de réfection à leur terme. Dirigeant des ouvriers dans une tentative de décrochage, prenant les dimensions de l'œuvre, essayant d'en enlever le cadre, arrachant les boiseries d'une porte, sa ténacité n'a pas de limites. Dans son obstination besogneuse, qui l'amènera à user d'explosifs, cet homme est aveugle à ce qui l'entoure. De la scène allégorique où des corps dansent au sol, comme sur une étrange mer de couvertures colorées, il ne saisit rien. Du temps qui passe, marqué par la venue régulière au centre du plateau d'un homme en costume, tirant successivement de sa poche des feuilles mortes, de la neige, des pétales de rose puis, enfin, du sable, il ne capte rien. Pas plus, d'ailleurs, que de l'ultime saison annoncée par l'effondrement de l'homme ensanglanté : celle de la mort et du sang. Ainsi, si la discorde pointe dès le début par des bruits sourds, des rumeurs et des lumières tourmentées arrivant de la porte $\mathrm{du}$ fond du plateau (point de fuite permanent de la création), rappelant peut-être l'histoire de la salle Rubens, qui fut pour partie détruite durant la Seconde guerre mondiale, la destruction gagne à la fin d'Het Land Nod tout l'espace. Cette fois ce ne sont pas des causes lointaines, inconnues, mais le résultat des actions du conservateur, qui demeure dans la scène finale seul face au tableau. Au-delà de l'idée de la permanence de l'art dans un monde traversé de soubresauts apparaît la position ambiguë de cet homme. Alors que sa fonction est de 
préserver et permettre la mise à disposition des œuvres d'art, son obstination, doublée d'une cécité quant à ce qui l'entoure, se révèle à l'origine du chaos général. Une dernière image troublante, qui invite à la mise en perspective du propos d'Het Land Nod. De par sa position sur le mur latéral gauche de la salle, Le Coup de lance échappe en effet partiellement aux regards des spectateurs. Ce faisant, l'œuvre d'art devient ici un prétexte (c'est bien le seul aveuglement qui mène le conservateur à la destruction), une ligne de fuite, permettant à FC Bergman d'échapper à un discours simpliste ou à un propos univoque.

Het Land Nod (Le Pays de Nod), conception FC Bergman

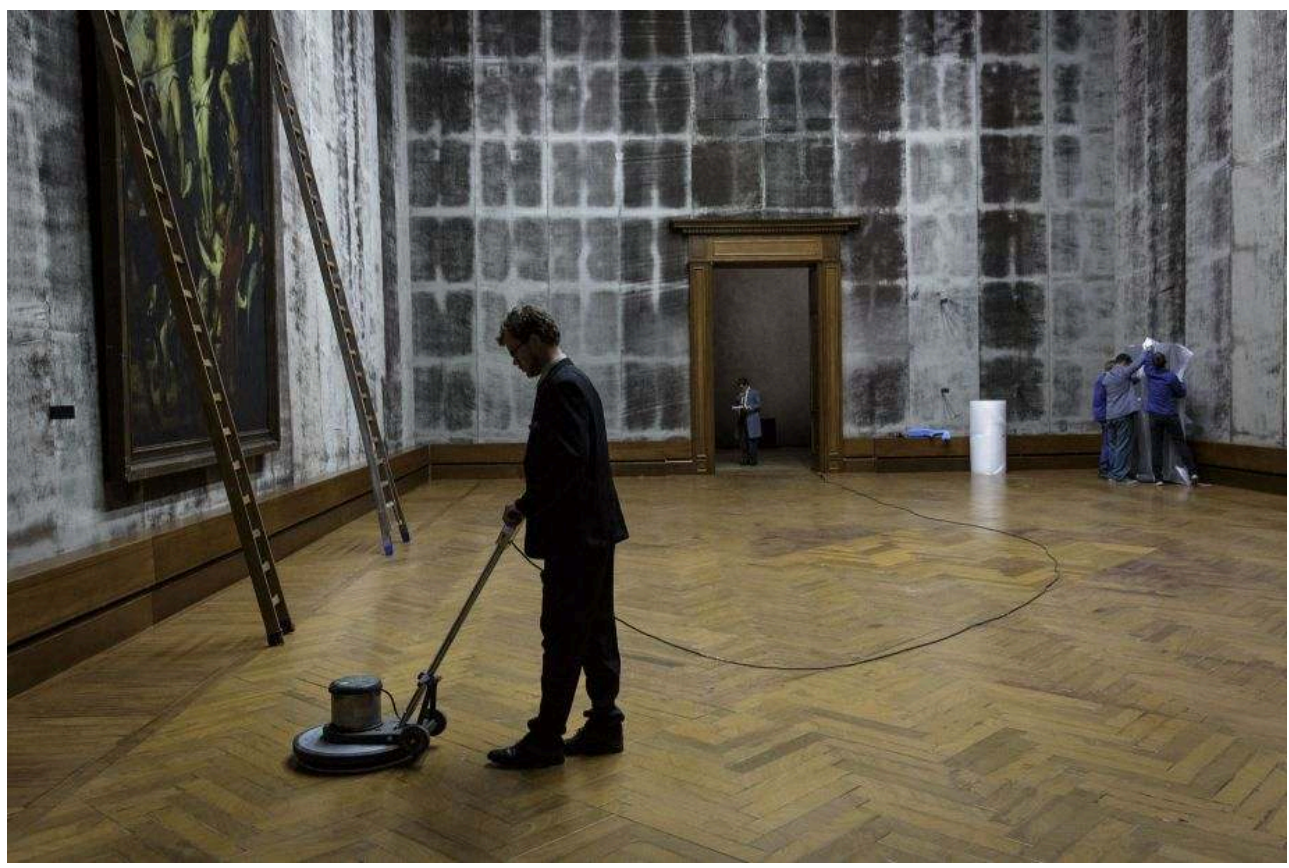

Christophe Raynaud de Lage 